\title{
REPRESENTAÇÕES DE DOCENTES UNIVERSITÁRIOS SOBRE A PROFISSÃO DOCENTE
}

\author{
Jefferson da Silva Moreira $^{1}$, Marinalva Lopes Ribeiro ${ }^{2}$ \\ 1. Bolsista de Iniciação Científica CNPq, Graduando em Licenciatura em Pedagogia, Universidade Estadual de Feira \\ de Santana, e-mail: moreirajefferson92@ yahoo.com.br; \\ 2. Orientadora, Professora Plena do Departamento de Educação, Universidade Estadual de Feira de Santana, \\ e-mail: marinalva_biodanza@hotmail.com;
}

Palavras-chave: Profissão Docente. Docência Universitária. Representações Sociais

\section{INTRODUÇÃO}

Nas últimas três décadas um conjunto de transformações econômicas, sociais, tecnológicas e culturais que se espalharam por todo o mundo, sob influência dos processos de globalização, impactaram as diversas profissões, ocasionando uma verdadeira crise quanto aos papéis tradicionais que elas desempenharam ao longo da história da humanidade. Na chamada "era da comunicação", computadores sofisticados, e todo um aparato tecnológico não apenas otimiza os processos, como muda as relações de trabalho, exigindo novas competências dos trabalhadores e, consequentemente, diferentes processos formativos voltados para a resolução de problemas de diversas naturezas (SOBRINHO, 2009). Nesse cenário, o mundo passou a conviver com uma avalanche de informações, dentro de um curto período de tempo, proporcionadas principalmente pelas Novas Tecnologias da Informação e da Comunicação (TIC's) e pela Internet. Todos estes aspectos incidem diretamente no exercício da docência e nos mobiliza a repensar os desafios impostos à profissão de professor na contemporaneidade, tendo em vista a perspectiva da qualidade do ensino que deve ser oferecida por esse segmento, além das transformações sociais ocorridas em decorrência de todo esse processo (MORAN, MASETTO e BEHRENS, 2013).

Nessa assertiva, estudos desenvolvidos no âmbito da Pedagogia Universitária anunciam a existência de problemáticas no que diz respeito aos conhecimentos profissionais de grande parte dos sujeitos que exercem a docência no Ensino Superior, a saber: lacuna no domínio de conhecimentos pedagógicos, didáticos, epistemológicos e filosóficos relacionados à Educação (D’ÁVILA, 2013). No tocante à profissionalização da docência universitária, é observável um silenciamento nos documentos oficiais acerca da formação necessária para o seu exercício. A Lei de Diretrizes e Bases da Educação Nacional (LDBEN 9394/96), por exemplo, no Art. 52, assevera ser o mestrado e o doutorado lugares privilegiados de "preparação" desses profissionais. Todavia, esse documento não explicita uma concepção de formação e das características que devem fundamentá-la. Todos esses hiatos se reverberam na frágil profissionalidade dos docentes universitários, isto é, no conjunto de saberes, atitudes e destrezas que deve constituir esse metier. Influenciados pelos desafios anteriormente apontados, empreendemos uma pesquisa, que teve por objetivo geral: analisar a possível existência de uma representação social entre docentes do ensino universitário sobre a construção da profissão docente. Para seu empreendimento, algumas questões pivôs foram levantadas: Quais representações possuem professores universitários, participantes de uma pesquisa-ação colaborativa, sobre a profissão docente? Quais elementos contribuíram para que eles escolhessem a docência universitária como profissão? Como esses profissionais aprenderam a exercer as atividades relacionadas ao ensino no contexto da Educação Superior? Destacamos que os resultados apresentados no texto 
em tela vinculam-se ao projeto de pesquisa "Inovação da prática pedagógica de professores do ensino universitário pela pesquisa-ação colaborativa", que é desenvolvido pelo Núcleo de Estudos e Pesquisas sobre Pedagogia Universitária (NEPPU). O quadro teórico do estudo está fundamentado nas discussões de autores do campo da Pedagogia Universitária; profissionalização, profissão e profissionalidade docente, representações sociais, além de produções teóricas que versam sobre a aprendizagem da docência e os processos de desenvolvimento profissional. A seguir, apresentamos o percurso metodológico da pesquisa.

\section{METODOLOGIA}

Esta investigação é de abordagem qualitativa. Um conjunto de pesquisadores, dentre eles, Lüdke e André (1986); e Minayo; (2001) afirmam que as principais características dessa concepção de pesquisa são: a obtenção dos dados acontece pelo contato direto entre pesquisador e objeto investigado; estes são de natureza predominantemente descritiva; há uma maior preocupação com o processo do que o produto da pesquisa; a análise dos dados segue um processo indutivo. Para o desenvolvimento deste estudo, valemo-nos, ainda, de alguns princípios teóricos e metodológicos da Teoria das Representações Sociais (TRS), que está pautada no paradigma de ciência emergente, por entender que a TRS pode nos propiciar uma compreensão holística da realidade e do fenômeno em questão neste estudo. Os sujeitos colaboradores desta pesquisa foram 9 professores universitários que atuam em diversos cursos de graduação da Universidade Estadual de Feira de Santana, tanto em licenciaturas, como em bacharelados, a saber: Letras, Geografia, Biologia, Enfermagem, Engenharia de Alimentos, Física e Química. Por questões éticas, deixamos de revelar seus nomes. Serão, portanto, identificados neste texto com a letra $\mathrm{P}$ (professor) seguido de um numeral.

No que tange aos dados produzidos para análise, tomamos como corpus de apreciação os diários reflexivos produzidos por esses profissionais ao final dos encontros de formação, que acontecem quinzenalmente, nesse locus de trabalho. Além disso, valemo-nos das transcrições das reuniões da pesquisa-ação com os depoimentos dos professores colaboradores. Para análise do material, aproximamo-nos da análise de conteúdo, técnica proposta por Bardin (1977), que se caracteriza por três etapas: a) préanálise, b) exploração do material, c) tratamento dos resultados, inferência e interpretação.

\section{RESULTADOS}

Os dados tomados como corpus de análise para a elaboração deste texto sinalizam que os professores participantes da pesquisa-ação colaborativa não escolheram deliberadamente exercer a profissão de professor universitário, conforme pode ser comprovado nos excertos a seguir:

\footnotetext{
$\mathrm{Na}$ verdade eu não fiz a escolha. Nunca tive esse interesse de ser professora universitária. Foi o que me apareceu como possibilidade de continuar morando no Nordeste após meu curso de Mestrado. Mas, sempre fui professora do ensino básico (Depoimento de P1).
}

Os motivos são tristes, pois não escolhi a docência, ela me escolheu por falta de opção e por falta de objetivos claros na minha vida. Embora tenha feito licenciatura, meu objetivo não era ser professora, por isso fui fazer o mestrado e depois o doutorado ainda pensando em não ser 
professora. Os concursos apareceram e eu passei, mas não queria (Depoimento de P2).

Fica evidente, no depoimento anterior, que o sujeito se viu "forçado" a escolher a profissão de professor. Quer dizer, não era um metier que admirava, que almejava para seu futuro, tendo em vista que "não queria". Se as representações sociais são construídas em contato com o grupo ao qual o indivíduo faz parte, provavelmente, a profissão de professor não tem tido o status que faça com que os sujeitos realizem uma escolha deliberada ou mesmo com que sejam estimulados pelos participantes desse grupo, como ocorre com outras profissões nas quais os jovens são incitados por amigos e familiares. Questionamos, em que medida essa escolha não deliberada pela docência universitária, vai ocasionar uma crise de identidade dos professores que atuam nesse segmento de ensino. Para Rios (2009, p. 119), a identidade não é constituída naturalmente, "a identidade aparece, assim, como algo construído nos limites da existência social dos indivíduos. Cada indivíduo ganha sua identidade no reconhecimento". Desse modo, podemos inferir que o modo como esses profissionais se reconhecem e se identificam incide, diretamente, na valorização que direciona à profissão docente. Outro colaborador da pesquisa, aqui denominado de P3, revela que dentre os motivos que o impulsionaram à escolha da docência universitária como profissão destaca-se a paixão pela área de conhecimento específico em que é formado: a Biologia.

\footnotetext{
Para mim foi uma sucessão de acontecimentos. Iniciei minha carreira no ensino fundamental e médio, após a conclusão do curso de licenciatura em Ciências Biológicas e depois de um tempo fui fazer mestrado e doutorado em Fisiologia Humana, na subárea de Neurociência. Durante a pós-graduação exerci algumas vezes o cargo de docente e após a conclusão tive a certeza de que essa seria realmente a minha carreira profissional. Os motivos foram vários entre eles posso destacar a paixão pela Biologia e o estudo permanente que ela proporciona, pois sempre se descobre coisas novas, o que a faz muito atraente, do meu ponto de vista (Depoimento de P3).
}

Fica evidente o fato de o "estudo permanente", que caracteriza a profissão de professor, ser um dos fatores que podem atrair os jovens para a escolha da profissão docente. É uma profissão na qual o sujeito é instigado a estudar permanentemente, a descobrir "coisas novas", a pesquisar a cada dia. Nesse sentido, concordamos com Freire (1998, p. 32), quando diz que "Não há ensino sem pesquisa e pesquisa sem ensino [...] Faz parte da natureza da prática docente a indagação, a busca, a pesquisa".

Acreditamos que todos esses aspectos vão incidir diretamente na constituição da identidade profissional dos professores universitários, denunciando que a docência no Ensino Superior constitui-se, ainda, um território frágil, no sentido da não configuração de uma profissionalidade entre os sujeitos que a exercem. Nesse sentido, recorremos às ideias de Pimenta e Almeida (2011) quando afirmam que o professor desse segmento de ensino tem sido historicamente caracterizado como aquele que domina os conteúdos específicos do seu campo de atuação, porém, não desenvolve as atividades relacionadas ao ensino de uma maneira eficaz. Em sua grande maioria, eles não possuem um conhecimento sobre os processos pedagógicos inerentes às atividades docentes na universidade. Atividades de planejamento, avaliação, organização das aulas, escolhas de metodologias e estratégias didáticas são feitas intuitivamente. Todavia, a docência universitária é uma atividade profissional complexa. O ensino é entendido como uma atividade intencional que requer o domínio de um conjunto de conhecimentos específicos, consolidados por meio 
de uma formação voltada exclusivamente para esse fim (PIMENTA e ALMEIDA, 2011).

\section{CONSIDERAÇÕES FINAIS}

Nossa pesquisa teve por objetivo geral analisar a possível existência de uma representação social entre os docentes participantes da pesquisa-ação colaborativa sobre a construção da profissão docente na Educação Superior. De modo geral, os resultados evidenciam que esses sujeitos desenvolvem as atividades de ensino intuitivamente, sem uma fundamentação teórica explícita sobre a natureza do ensino. Todavia, os mesmos destacam que a formação continuada, a troca de experiências entre os pares e a reflexão sobre a própria prática pedagógica são elementos impulsionadores dos seus processos de aprendizagem da profissão docente.

Nesse sentido, os dados empíricos revelam fragilidades no âmbito da profissionalidade dos sujeitos colaboradores da pesquisa, aspectos que podem estar atrelados à não existência de uma política de formação continuada e de desenvolvimento profissional para os docentes da Educação Superior. Todavia, com a participação nesta pesquisa-ação colaborativa os professores têm tido a oportunidade de refletir sobre suas práticas, teorizar sobre elas, e experimentar inová-las. Tais reuniões oportunizam, ainda, revisões em suas atividades profissionais no que concerne à natureza do ensino. Os depoimentos dos professores desvelam, assim, mudanças que eles têm procurado realizar no cotidiano da sala de aula universitária. A participação em propostas de formação continuada e a troca de experiência entre os pares são elementos importantes para o impulsionamento dos seus processos de desenvolvimento profissional, na medida em que os retira da condição de meros expectadores de propostas de formação continuada elaboradas por outros agentes.

Nesse sentido, esta pesquisa-ação colaborativa tem dado passos substanciais na sua concretização, tendo em vista que pode contribuir para que os professores possam refletir sobre as suas práticas, com vistas a transformarem em práticas inovadoras. Sinalizamos, por fim, a necessidade da criação de uma política institucional na universidade locus desse estudo, com o objetivo de proporcionar aos seus professores refletirem sobre as ações pedagógicas que desenvolvem no cotidiano do seu ambiente de atuação profissional.

\section{REFERÊNCIAS}

BARDIN, L. Análise de conteúdo. 1977.

BRASIL. Lei de Diretrizes e Bases da Educação Nacional. 1996.

D'ÁVILA, C. M. Docência na educação superior: labirintos e saídas na construção da profissionalidade docente. In: Profissão docente na educação superior. D'Ávila, C. M; Veiga, I. P. (Org.). 1. ed. - Curitiba, PR: CRV, 2013.

DIAS SOBRINHO, J. Professor Universitário: contextos, problemas e oportunidades. In: CUNHA, M. I. et. al. (Orgs). Docência universitária: profissionalização e práticas educativas. Feira de Santana: UEFS Editora, 2009.

LUDKE, M; ANDRÉ, M. Pesquisa em Educação: abordagens qualitativas. São Paulo: EPU, 1986.

MINAYO, Maria Cecília de Souza (org.). Pesquisa Social: Teoria, método e criatividade. 18 ed. Petrópolis: Vozes, 2001.

MORAN, José Manuel, MASETTO, Marcos; BEHRENS, Marilda. Novas tecnologias e mediação pedagógica. 7. Ed. São Paulo, SP.: Papirus, 2003. 